\title{
Impact of intermittent dietary restriction on the health-related outcomes of faith-based fasting
}

Abdelhadi Halawa(1)

\begin{abstract}
Background and purpose: For much of the history of studying the effects of intermittent fasting on the health of people who engage in fasting for religious reasons, there has been no conclusive evidence-based consensus on the health outcomes of this form of intervallic fasting. The purpose of the present study is to examine the healthrelated outcomes of intermittent faith-based fasting. Whereas there are several forms of faith-based and non-faith based fasting, the present study will be primarily dedicated to examining the health effects associated with one of the most ubiquitous forms of religious fasting practiced globally by the preponderance of the eligible adults among 1.8 billion Muslims, which is fasting during the annual Islamic month of Ramadan. Therefore, Ramadan fasting provides a significant research paradigm to investigate the health effects of intervallic fasting in humans.
\end{abstract}

Methods: A systematic review and meta-analysis methodology was employed to search major databases, printed books, and official web-based electronic publications to identify and select a multitude of relevant peer-reviewed studies on the health effects of faith-based intermittent fasting. The data garnered from the selected studies were systematically reviewed, analyzed, and combined. The findings were compared and examined to evaluate whether there were patterns of significant or no significant results of specific health-related effects associated with intermittent faith-based fasting.

Results: The systematic review and data analysis suggest that Ramadan intermittent fasting is associated with both health risks and health benefits. The most vulnerable group of people who are most at risk for exposure to adverse health effects of fasting are those individuals who fast Ramadan with underlying pre-existing health conditions such as diabetes, asthma, kidney, and cardiovascular diseases, which can be exacerbated by the daily fasting for long hours.

Conclusions: The health outcomes of intermittent fasting and voluntary caloric restriction are prefatory and inconclusive The findings of the present study suggest that there is scientific evidence to support the hypothesis that intermittent fasting and forms of meal timing schedules may be associated with both favorable and unfavorable health outcomes. Fasting individuals with adverse pre-exciting health conditions would benefit significantly from seeking a pre-Ramadan medical evaluation, personalized dietary counseling, and Ramadan fasting-tailored health and wellness education as imperative interventions to avert potential medical crises and reduce any further health complications.

Keywords: Faith-based fasting, Intermittent dieting, Day-time dietary restriction, Ramadan, Islam, Global Muslim population, Health effects of fasting

Correspondence: ahalawa@millersville.edu

Millersville University, Millersville, PA, USA

(c) The Author(s). 2020 Open Access This article is licensed under a Creative Commons Attribution 4.0 International License, which permits use, sharing, adaptation, distribution and reproduction in any medium or format, as long as you give appropriate credit to the original author(s) and the source, provide a link to the Creative Commons licence, and indicate if changes were made. The images or other third party material in this article are included in the article's Creative Commons licence, unless indicated otherwise in a credit line to the material. If material is not included in the article's Creative Commons licence and your intended use is not permitted by statutory regulation or exceeds the permitted use, you will need to obtain permission directly from the copyright holder. To view a copy of this licence, visit http://creativecommons.org/licenses/by/4.0/. 


\section{Introduction}

For millennia, different forms of fasting have been practiced by many people for various reasons. Most faithbased fasting has been promoted and practiced by earlier priests, priestesses, and worshipers in preparation to spiritually amalgamate with or approach deities and divine beings. Furthermore, in ancient Egypt and Greece, fasting was employed as prophylactic and therapeutic interventions by high priests and physicians. Patients who exhibited certain symptoms of illness were prescribed to refrain from consuming food or drink. The origin of religious fasting can be traced back to the Hellenistic mystery religions such as the "healing cult" of the god Asclepius (the ancient Greek god of medicine), which was practiced in the earlier centuries of the GrecoRoman period. At that time, individuals were provided with spiritual experiences that were not provided by the official public religions. During that period, the deities were thought to unveil their godly power of knowledge and teachings in visions and dreams but only after a prerequisite period of fasting by the disciples that is fulfilled as a sign of their absolute devotion to the deities. Another ancient form of fasting for religious purposes was practiced by the pre-Columbian peoples of Peru as a consecrated requirement for seeking penance where individuals had to confess their sins before a priest. In some ancient cultures, fasting was deemed to be a type of offering to attenuate the wrath of a displeased deity or to facilitate the resurrection of a deity who was believed to had been deceased [1].

Whereas faith-based fasting has been predominantly practiced to satisfying prescribed religious requirements, physiologically, it could potentially have significant effects on the health of fasting individuals. Therefore, investigating potential health effects can provide insights on the cause-effect relationship and inform the fasting public and healthcare providers of guidelines and interventions to mitigate any potential detrimental health effects. Although there are distinct differences in the fasting duration and length of daily fasting, when fasting occurs in a particular year, the modality of fasting (partial or total), and the specific purpose for fasting, they all have common objectives of exhibiting religious devotion to a deity, self-discipline, self-purification, and health maintenance. Irrespective of these differences, the impact of fasting on human health can be substantial because faith-based fasting is commonly practiced globally by numerous religious groups with diverse health conditions and dietary needs, chiefly among them Muslims during the month of Ramadan and Greek Orthodox Christians during the three periods of fasting known as Nativity, Lent, and the Assumption. Further, there is the Daniel Fast practiced by Evangelical Protestants in the USA wherein the believers abstain from consuming any meat and wine replacing them with fruits, vegetables, and water for 3 weeks to come closer toward God. Moreover, faith-based fasting has been practiced for centuries in different forms and length of time ranging from a few hours, a few days, or even a few weeks by other religions, including Buddhism, Taoism, Jainism, Hinduism, Seventh-Day-Adventism, and Judaism in which a lifetime kosher diet is required to be followed by Jewish devotees. In Judaism, dating back to biblical times, Yom Kippur fasting has been practiced by reflecting and repenting for one's sins and seeking forgiveness [2-6].

Islam is one of the three major globally recognized religions. It was founded by the Prophet Mohammed in 610 A.D. in the city of Mecca in the Arabian Peninsula, present-day Saudi Arabia. By 630 A.D., Islam began to spread out beyond the Arabian Peninsula to other parts of the world, especially eastward into Central Asia and China through commercial and cultural exchanges by traveling merchants, missionaries, emissaries, and mariners traversing the ancient Silk Road overland and maritime trade routes [7, 8]. According to a global population study by [9], the Muslim population is estimated to grow globally from 1.8 billion in 2015 to nearly three billion in 2060 (Fig. 1). Islam is founded on observing five foundational pillars that are required by all Muslims to follow and adhere to wherever they reside.

The first pillar is Al-shahada (Arabic: الثهادة, al-šhādah) or testimony affirming that there is no deity except Allah, and that Muhammad is his Prophet and his messenger. The second pillar is performing five daily prayers (Arabic: الصلاة, șalawāt) distributed throughout the day. The third pillar is Al-Zakat (Arabic: الزكاة, za'ka:h), which is paying alms (charity tax) to benefit the poor and needy Muslims. The fourth pillar is annually fasting the month of Ramadan (Arabic: صوم, sawm). The fifth pillar is performing Hajj (Arabic: الحج, Hağğ), which is an annual religious pilgrimage to Mecca by all qualified adult Muslims once in their lifetime [10]. As one of the abovementioned pillars of Islam, Ramadan is the 9th month of the Islamic calendar, which is determined based on a 12-month lunar year that consists of nearly 354 days. Depending on the sighting of the lunar moon, Ramadan can last between 28 and 30 days. Fasting begins at the pre-dawn time by eating the last meal before fasting called "Suhoor" (Arabic: سحور, Sohoor) and ends at dusk by eating the first meal after fasting called "Iftar" (Arabic: Efftar) or breaking the fast. Contingent upon the time zone of a geographical region, altitude, and latitude, and the season of the year is where Ramadan is declared. On average, Muslims may fast between 12-19 h per each Ramadan day. When approaching adolescence, all male and female Muslims who are physically and mentally able are obligated to fast the entire month of Ramadan. However, there are several exemptions from fasting due to hardships. These exemptions 


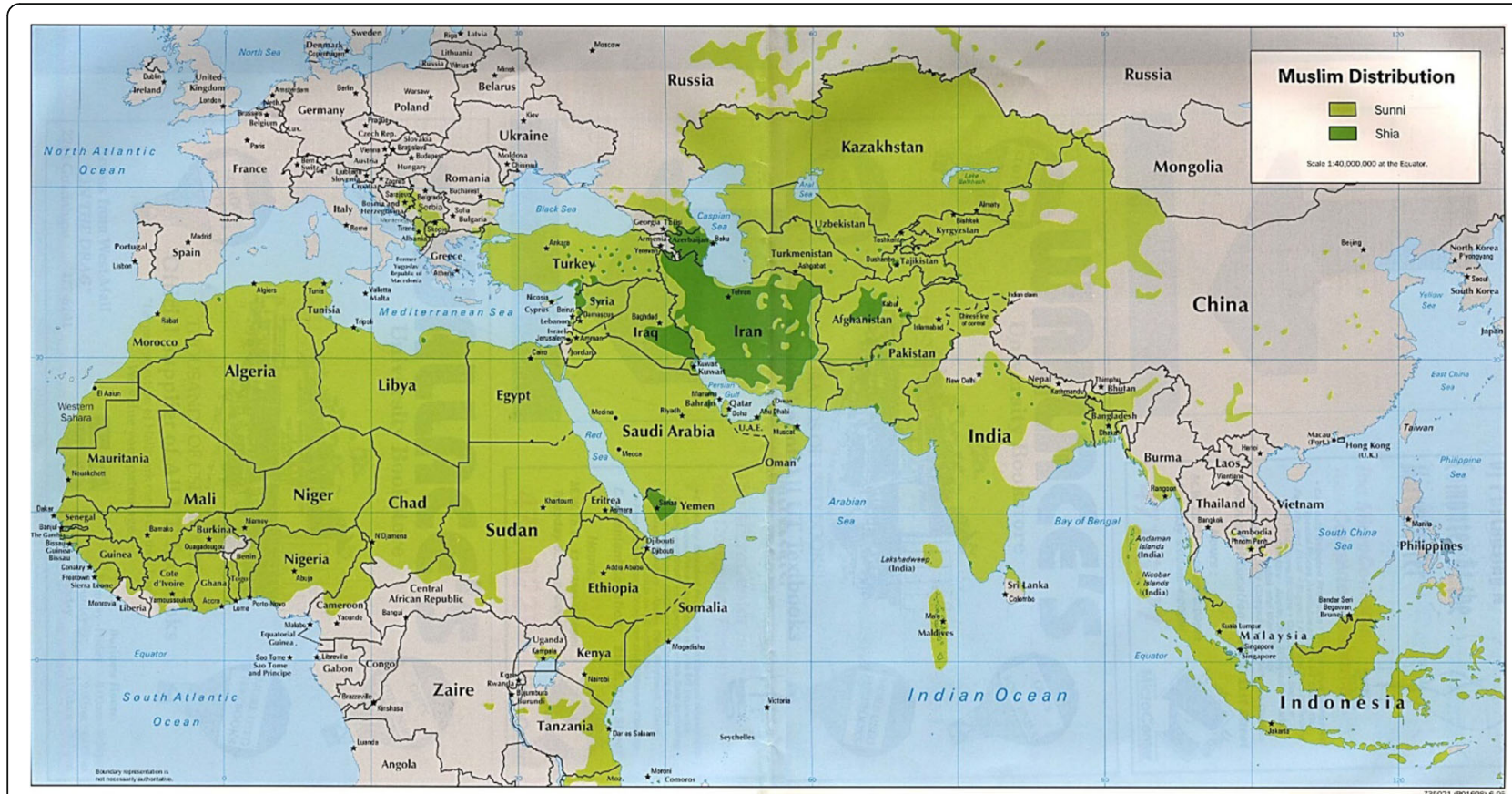

Fig. 1 Map of the global Muslim population distribution illustrating Sunni Muslims in lighter green and Shia Muslims in darker green where Ramadan fasting is observed for 1 month every year (2015). Source: The University of Texas Library, Austin, Texas,

USA. http://www.lib.utexas.edu/Libs/PCL/Map_collection/world_maps/Muslim_Distribution.jpg

include pre-pubescent children, individuals who are traveling long arduous distances, taking medication, sick, pregnant, lactating, menstruating, or suffering from chronic debilitative conditions are legitimately exempt from fasting $[11,12]$.

Faith-based and other forms of fasting for enhancing people's health conditions and life expectancy have been the focus of a myriad of scholarly investigations. However, findings from other investigations suggest that during fasting Ramadan, there is a propensity for consuming more food that is rich in saturated fat, sugar, LDL cholesterol, and processed carbohydrates. This unhealthy diet poses greater risks for cardiovascular disease, obesity, and type 2 diabetes, especially for diabetic fasting individuals [13]. Findings obtained from the preponderance of these investigations regarding the health outcomes of fasting reported mixed results. Arriving at these mixed results can be attributed to several factors: first, the study participants' baseline health conditions prior to fasting; second, the number of days of fasting; third, the duration of daily fasting; fourth, the participants' food choices and the amount of food and calories they had consumed; fifth, the participants' demographics such as gender, age, level of education, and income; and six, whether fluid intake is allowed during the fast periods. However, many studies have indicated greater similarities between the fasting groups during the faith- based month-long Ramadan and the non-faith-based health improvement-based alternate-day fasting (ADF), which is also a form of intermittent fasting. ADF comprises of fasting 1 day, eating on the next, and repeating the same pattern on the ensuing days. Whereas in Ramadan, people fast during the daylight part of the day, which typically averages between $12-19 \mathrm{~h}$ each day and eat and drink during the remaining nighttime part of the same 24-h day (Fig. 2). There is another key distinction between the two intermittent fasting practices, which is that fluid intake is permitted during all the time of the ADF practice, whereas fluid intake is prohibited during the fast periods of the month of Ramadan [14, 15].. Several studies examined the negative health outcomes of fasting during Ramadan that were caused by a significant change in the dietary behaviors of most Muslims. In comparison with the non-fasting months of the year, traditionally during Ramadan, many Muslims are more inclined to consume larger food portions and more frequently consume greater quantities of sweetened food and beverages. In addition to consuming one sizable meal at iftar time (sundown) and another lighter meal before dawn, they also might consume an additional meal before going to sleep [16-18]. Furthermore, [18] reported that despite the reduction in the frequency of daily meals during Ramadan, there was no corresponding significant reduction in subcutaneous fat, body 


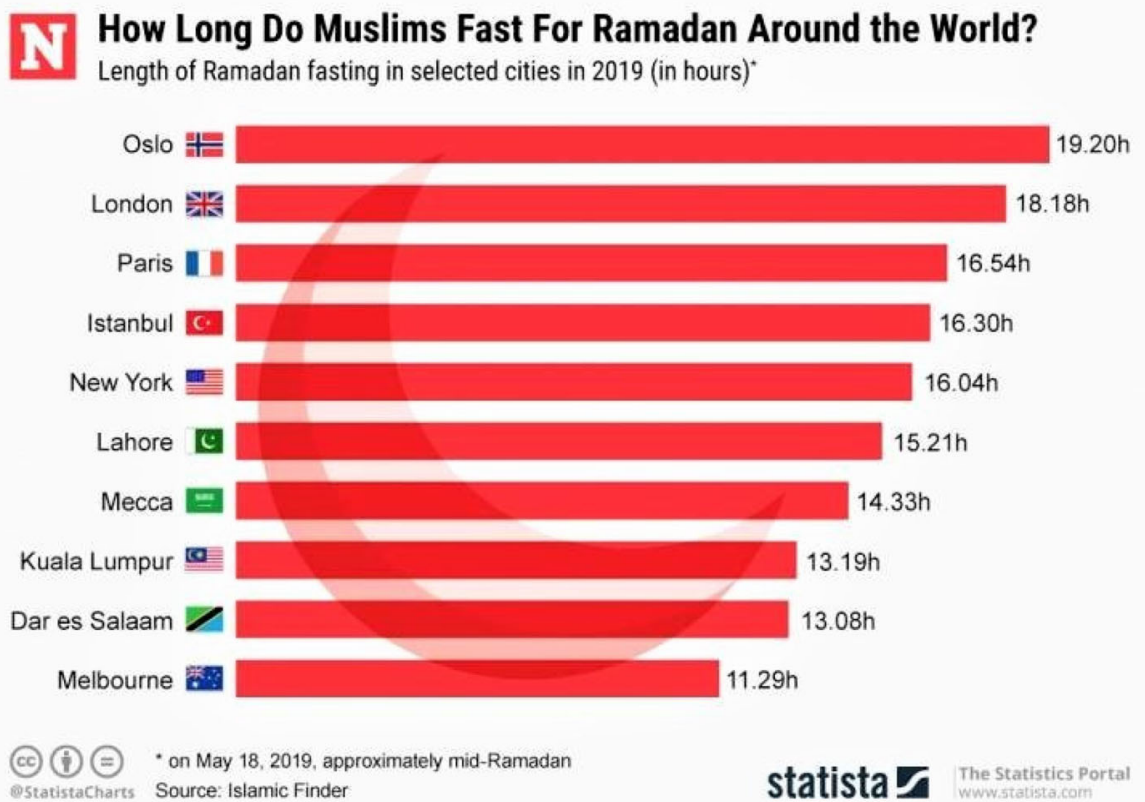

Fig. 2 Illustrates the different lengths of fasting times worldwide based on the geographical, latitude, and altitude of the location of each country (2019). Source: Waterfield, S. Newsweek. https://www.newsweek.com/ramadan-2019-muslim-holy-month-fasting-islam-1406764

weight, or lean body mass. Similarly, research by [19] found that as a result of altering their eating habits and food selection during Ramadan, coupled with a lack of physical inactivity, Muslims in Saudi Arabia increased their energy intake from refined crabeaters, dates, sweets, and sugary beverages. As a result, $59.5 \%$ of the study participants reported weight gain after Ramadan further increasing the risk of pre-existing high rates of type 2 diabetes.

Concerning the favorable health outcomes associated with Ramadan fasting, [20] found that during Ramadan fasting, Ghanaian teenagers (younger than 15 years old) markedly improved the quality of their dietary habits, considerably reduced their daily meal frequency, increased their food diversity, and significantly reduced their body weight. In similar research, [21] maintained that despite the fasting of Ramadan, there were no changes in pre-Ramadan, end of Ramadan, and 1 month after Ramadan in the baseline blood pressure, anthropometric measures, lipid profile, and body composition in both the adult male and female Thai participants. Consistent with the above findings, [22] reported that fasting Ramadan resulted in a measurable reduction in meal frequency, significant weight loss, and a decrease in daily energy intake. However, there was a significant upsurge in dietary fat intake (35.84 vs. $25.36 \%$ ), especially in saturated fat and dietary cholesterol. Excluding three cases, there was no recording of recurrent hypoglycemic incidents among the study participants. Similarly, Ramadan fasting was associated with inducing weight loss for both adult males and females; however, body percent fat was reduced only in males by $2.5 \%$ [13]. Similar research in healthy male and female adults (aged 25-58 years) showed that fasting Ramadan did not change oxidative stress parameters or biochemical markers of cellular damage [23].

Fasting Ramadan can be a major challenge to getting adequate uninterrupted sleep for many Muslims. Typically, the fasting devotees break their fast at sunset (iftar) by eating a substantial meal, and they eat another meal again for dinner before going to sleep. They also eat a pre-dawn third meal (Suhoor) before starting the fast [24]. This pattern during Ramadan leads to delaying the onset of sleep. As a result, the normal sleep pattern can be disrupted, particularly the rapid eye movement (REM) stage of sleep. This repeated interruption in sleep pattern was associated with irregularities in the metabolic and endocrine functions of study participants during Ramadan [18]. The findings reported by [18] were corroborated by [25] who suggested that intermittent Ramadan fasting resulted in a reduction in the REM stage of sleep; however, there was no effect on the other sleep stages, daytime sleepiness, or the arousal index. In an epidemiological study, alteration in the sleep/wake pattern during Ramadan has been shown to alter serum cortisol values in study participants. Alteration in 
cortisol levels was associated with changes in sleeping patterns and duration [26]. Several studies examined the health effects of making intermittent changes in mealtimes to accommodate the fasting requirements during Ramadan through sleep/wakefulness episodes. Findings from these studies showed that altered mealtimes, sleep patterns, and circadian rhythms were associated with increased risk factors for metabolic, endocrine, and gastrointestinal problems [27-29]. Clinical evidence demonstrated that an interrupted or restricted sleep pattern during the normal circadian nighttime cycle in Ramadan causes daytime fatigue, which has been associated with impaired cognitive and kinetic physical functioning [30]. Furthermore, the effects of fatigue engendered by interrupted or inadequate sleep can adversely affect basic daily functions, including work performance, personal and public traffic safety, and operating machinery [31]. Chronic fatigue-related stress is known to alter the neural circuits in the brain and adversely affecting the cognitive and behavioral functions. Findings from clinical research indicated that repetitive sleep/wake pattern contributes to the development of an array of diseases, including impaired immune function, hypertension, atherosclerosis, and insulin-resistant metabolic disorder [32]. According to [33], the major changes made in regular sleep patterns and circadian rhythms during the month of Ramadan could adversely affect the individuals' sensory and neurological functions. These affected functions are associated with an increased incidence of traffic accidents, decreased work hours, and diminished overall work productivity. However, several studies juxtaposed the rates of traffic accidents during Ramadan with those of the non-Ramadan months. The results showed that the rates of traffic accidents were either unchanged or slightly higher in Ramadan than those in the non-Ramadan months. Moreover, traffic accidents involving fatalities were slightly higher, whereas the rates of property damage were lower [34-36]. Related research on driving behavior and observing traffic rules during Ramadan indicated that the rate of wearing seatbelts, speeding, and gratuitous horn-honking was comparable to that of the non-Ramadan months [37].

\section{Materials and methods}

\section{Data collection and search strategy}

A comprehensive systematic search and review of relevant scientific literature methodology were employed to identify peer-reviewed research articles in major bibliographic databases, including PubMed, BMC Public Health, Global Health, CrossRef, Scopus, Google Scholar, and Medline. Additionally, the bibliographic search encompassed printed books and credible official web-based electronic publications with expertise in the health effects of forms of intermittent fasting (Fig. 3). A

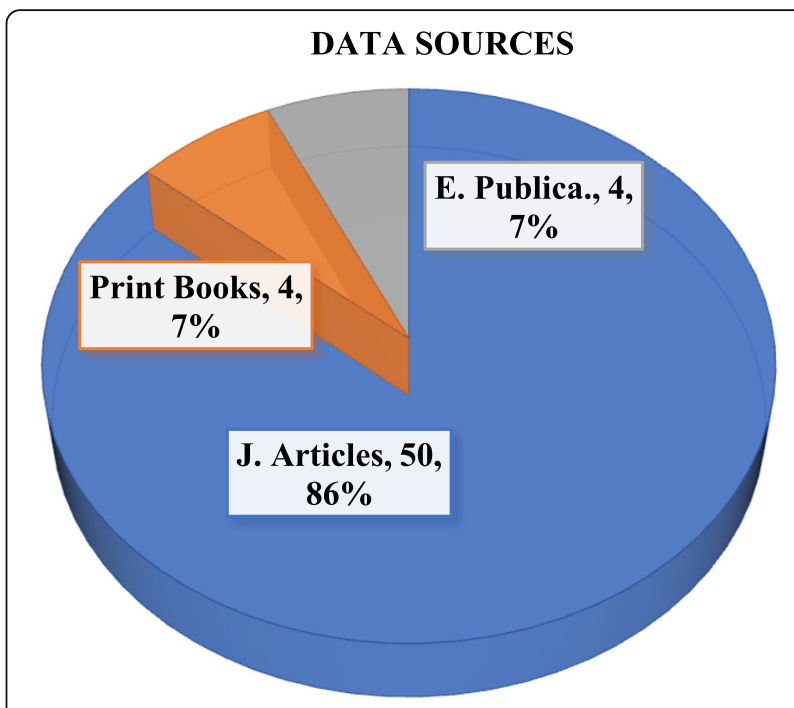

口J. Articles $\square$ Print Books $\square$ E. Publica.

Fig. 3 Depicts the ratio (\%) of data sources obtained from peerreviewed journal articles (J. articles), printed books (print books), and web-based electronic publications (E. Publica.)

multitude of wide-ranging cognate content and peerreviewed research articles that investigated the healthrelated effects of the faith-based intermittent fasting were searched, identified, and selected for review. The results garnered from the review were quantitatively analyzed and compared. The findings from the reviewed studies were then integrated and examined to answer the study question, which is whether there are patterns of significant or no significant results of specific healthrelated effects associated with intermittent fasting, primarily fasting during the Islamic month of Ramadan. The strength of evidence, as well as the extent of consensus among the findings generated from the reviewed studies, was also assessed.

\section{Results}

In the present study, fifty (86\%) peer-reviewed scholarly articles, four (7\%) printed books, and four (7\%) webbased electronic publications (Fig. 3) were selected and systematically reviewed to classify the health effects of fasting. The findings were then compared, combined, and analyzed. The data analysis revealed that there is strong evidence supporting both the hypothesis of health benefits and the hypothesis of the detrimental health effects of fasting during the month of Ramadan. The analysis of the consolidated findings revealed that there is a lack of conclusive quantitative or qualitative unanimity supporting the hypothesis of beneficial effects over the hypothesis of the insalubrious effects of intermittent fasting. The insufficiency of conclusive unanimity among 
the results can be reasonably explained by the fact that whereas Ramadan fasting is consistently performed homogeneously by all Muslims regardless of their cultural background or topographical location, there are greater dissimilarities among most Muslim countries in their dietary habits, culinary traditions, cultural diversity, lifestyle, distance from the equator and length of daily fasting, and the individual's pre-existing health conditions that might have significantly contributed to the ambivalent results of the health outcomes of Ramadan fasting (Fig. 1).

Several studies indicated numerous physical and affective health benefits associated with Ramadan fasting. These health benefits encompass salubrious changes in the Hematological-Biochemical Index [38]; improvement in body weight and metabolic parameters linked to type 2 diabetes, cardiovascular disease, and certain forms of cancer [39]; favorable effects on the underlying disease process in subjects with asthma [40]; positive changes in body weight and improvement in particular biochemical parameters in healthy subjects, especially in men [41]; fasting serves as an effective therapeutic process that might enable patients to cope with and recover from mild to severe health conditions [42]; stimulates greater optimism and was socially beneficial to the overall wellbeing, and strengthening family bonding [43]. In juxtaposition, many other studies presented evidence of numerous insalubrious health outcomes associated with Ramadan fasting chiefly among them, and fasting may cause some adverse health effects in the patients who are fasting with pre-existing health conditions such as hypertension, high levels of LDL cholesterol, abnormally high level of uric acid in the blood, hyperglycemia, cardiovascular disease, and liver and kidney diseases [44]; fasting has been connected with experiencing frequent headaches, heartburns, constipation, dehydration, diminished sleep quality, and anemia [45]; fasting has been often related to major cardiovascular events in patients with chronic kidney disease [46]; individual with preexciting health conditions may have significant adverse effects on the glycemic and insulin regulations, blood lipid profile, weight control, and dietary intake [47]; Ramadan fasting-related changes made in dietary habits, physical activity, and sleep patterns may have negative effects on the glycemic and insulin regulations, blood lipid profile, weight control, and dietary intake [48]. Founded on the analysis of the evidence garnered from numerous studies, it seems that unhealthful dietary habits, significant cultural and environmental differences, circadian rhythms effects on the central and peripheral nervous systems, and pre-existing underlying health conditions play a key role as contributing factors in determining the health outcomes of intermittent fasting.

\section{Discussion}

As one of the five pillars of the Islamic faith, fasting in the month of Ramadan is a religious obligation to be observed by most of the eligible 1.8 billion Muslims worldwide (Fig. 1). As a ritual, whereas Ramadan fasting is invariably observed uniformly by all Muslims regardless of where they reside, there are inherent prodigious cultural diversity, indigenous food influences, unique lifestyles, and indigenous culinary practices of each Muslim community. Every Muslim population and culture in a geographical region, such as in the Middle East, Europe, Africa, Central Asia, Southeast Asia, and Southwest Asia have distinctive cooking styles, eating habits, and diverse homegrown food choices that are widely distinctive from the other Muslim populations and geographical regions. These wide-ranging food choices, gastronomies, and indigenous dietary habits coupled with different time zones and environmental and climatic conditions may contribute to varying degrees of the health outcomes of the month-long intermittent daytime fasting of Ramadan on those diverse global Muslim populations (Fig. 2). More significantly, the duration of daylight and number of daily fasting hours vary greatly based on the geographical location of a certain Muslim country and its orientation to the equator. The geographical location and distance from the equator are critical as they can make a significant difference from country to country regarding the number of hours of the daylight time, which is critical to determine precisely the start and end of the daily fast (Fig. 2). The aforesaid wideranging differentiating factors among the findings explain the reason for the absence of homogenous results concerning the health-related outcomes of the month of Ramadan intermittent fasting. The absence of homogeneity of the results extracted from the studies reviewed in this investigation underscores that the wide-ranging geographical and cultural differences in food selection, cooking styles, dietary habits, duration of the daily fasting time, varied time zones, and the baseline health condition of the fasting individuals, played a seminal role in determining the health-related outcomes of the intermittent fasting during the month of Ramadan (Fig. 1).

Concerning the health benefits of Ramadan fasting, the analysis of the data obtained from the reviewed studies demonstrated that some of the findings support the hypothesis of potentially experiencing favorable health outcomes as a result of fasting Ramadan. Findings reported by [38] indicated that in conjunction with physical activity, Ramadan fasting produced positive changes in the Hematological-Biochemical Index of the study participants. Similar findings by [39] found several health benefits, including improvement in body weight 
and metabolic parameters linked to type2 diabetes mellitus, cardiovascular disease, and certain forms of cancer [40] maintained that alternate day calorie restriction (ADCR) facilitated speedy and sustained beneficial effects on the underlying disease process in subjects with asthma, suggesting a novel approach in the treatment of asthma. Reduction in body weight was frequently suggested in several studies as one of the favorable health outcomes of Ramadan fasting. Research by [41-43] compared body weight in the pre-Ramadan months with that of after Ramadan. The findings revealed that fasting was effective in decreasing body weight, as well as improving several biochemical parameters in healthy subjects, especially in men. Psychosocially, research by [44] postulated that fasting Ramadan can serve as an effective therapeutic process that can help patients to cope with and recuperate from mild to severe health conditions [44]. further expounded, fasting study participants described having a feeling of inner peace, restraining anger, being more willing to doing good deeds, exercising selfdiscipline, and preparing oneself to be a good Muslim, as well as a good person. Similarly, affectively, [45] observed that whereas study participants reported some difficulty managing their fasting dietary needs due to hypoglycemia concerns, they also reported optimism regarding fasting Ramadan. They believed that Ramadan fasting was socially beneficial to their overall well-being, and Ramadan fasting provided appropriate time and opportunity to spend on strengthening family bonding, especially during commensality at iftar mealtime (breaking the fast).

Conversely, regarding the adverse health outcomes of Ramadan fasting, findings from similar but different studies support the hypothesis of potentially experiencing some unfavorable health outcomes resulting from fasting Ramadan. Research by [46] maintained that Ramadan fasting may produce some harmful health effects in the patients who are fasting with unwell conditions, including hypertension, elevated levels of LDL cholesterol, abnormally high level of uric acid in the blood, hyperglycemia, cardiovascular disease, and liver and kidney diseases. In line with the findings by [46], research by [47] reported a few health problems that are typically associated with some fasting individuals during Ramadan, chiefly among them experiencing headaches, recurrent heartburns, constipation, dehydration, diminished sleep quality, and anemia. Similarly, [48] found that as a result of fasting Ramadan, major cardiovascular events (MACE) emerged more frequently in patients with chronic kidney disease, especially patients with preexisting cardiovascular disease, which was predicted by an early rise of serum creatinine. In their findings, [49] stated that though Ramadan fasting is generally safe for most healthy individuals, because of potential health risks, those with various unfavorable pre-exciting health conditions should consult with their health care providers and follow their medical recommendations [50] asserted that the major changes made in dietary habits, daily physical activity, and sleep patterns during Ramadan may have significant effects on glycemic and insulin regulations, blood lipid profile, weight control, and dietary intake. Therefore, diabetic patients are recommended to have a pre-Ramadan medical examination, as well as diabetes and dietary education to reduce their health risks during fasting. Research by [51] compared incidents of headaches reported to medical facilities during the month of Ramadan to the non-Ramadan months and found significantly higher rates of headache cases reported to hospitals during Ramadan due to dehydration, sleep deficiency, and other Ramadan fasting-related factors [52] examined the physical performance of female athletes during the month of Ramadan. The findings showed that Ramadan fasting significantly reduced both body weight and body mass index (BMI) $(P=0.01)$. However, it has not improved the overall physical performance of gymnastic female athletes. In a similar study on cognition, [53] investigated the effects of Ramadan fasting on the cognitive function in a group of healthy Muslim athletes. The findings revealed that cognitive performance in functions requiring sustained rapid responses was better in the morning; however, it declined in the late afternoon, whereas performance in non-speed dependent accuracy measures remained steadily resilient. Similar effects of fasting on physical performance reported by [54] who posited that blood sugar and tissue hydration decreased progressively throughout the fasting hours of daylight. Some limitations of anaerobic energy, endurance performance, and muscular strength were decreased as well. Muscle glycogen and body fluid reserves and reduced blood glucose were recorded. This reduction in physical performance parameters may cause a depressed mood state, an increased perception of less effort, and may lead to poorer teamwork. Research by [55] on the alternation of dietary and smoking patterns inspired by fasting during Ramadan found that consumption of tobacco products, tea, and coffee are markedly declined. Comparably, [55-57] observed a significant decline of $50 \%$ of the average number of cigarettes smoked, as well as higher rates of smoking cessation interventions during the month of Ramadan.

\section{Conclusions and future research recommendations}

The current scientific evidence concerning the health effects of intermittent fasting is prefatory and inconclusive. The results of the present study corroborate the hypothesis that various forms of intermittent fasting and meal timing plans may be associated with both favorable and 
unfavorable health effects. The results demonstrated that intermittent fasting and caloric restriction may provide favorable health outcomes for some people and unfavorable health outcomes for others. Several factors may influence the health outcomes of Ramadan intermittent fasting, including underlying pre-existing health conditions, Ramadan-specific dietary patterns, the time zone of each geographical region and its altitude and latitude, effects of environmental temperature, the total number of daily fasting hours, and the season of the lunar calendar where Ramadan fasting is declared. These results of the current study may provide beneficial insights and actionable guidelines to decrease and mitigate the health risks for those fasting individuals who might have preexisting health conditions to enable them to manage Ramadan fasting with their health and well-being as the foremost priority. Whereas the current study mostly focused on examining the health effects of fasting during the Islamic month of Ramadan, however, the results can be extrapolated and implemented to include comparable faith-based and non-faith-based forms of intermittent fasting such as the non-faith-based health improvementbased alternate-day fasting (ADF).

The current study provided sufficient scientific evidence that is taken as a whole; for the preponderance of healthy Muslims who fast, Ramadan, it can provide health and well-being benefits in the following outcomes: (1) reducing the risk factors for gastrointestinal and metabolic disorders, (2) fasting for nearly 1 month can help overweight and obese individuals in reducing and managing excess body weight more effectively, (3) lowering abnormally high blood lipids, especially LDL cholesterol, (4) decreasing elevated blood glucose levels and reducing and controlling the risk of type 2 diabetes, and (5) improving spiritual and psychosocial health outcomes. In juxtaposition, the results of the present study also postulated that although they are legitimately exempt from fasting due to illness or infirmity reasons, the data analysis indicated that the most vulnerable group of people who are susceptible to experience various unfavorable health effects related to fasting are those individuals who do not believe that they are ill enough; however, they still attempt to fast, Ramadan, while experiencing pre-existing health conditions such as kidney disease, asthma, diabetes mellitus, cardiovascular disease, and hypertension are more likely to be at higher risks for further health complications. In order to prevent or reduce potentially complicating risk factors, the fasting individuals with pre-existing health conditions can benefit considerably from (1) considering not fasting as it is permissible under the fasting hardship exemptions, (2) undergoing pre-Ramadan fasting comprehensive medical evaluation, (3) seeking a personalized professional dietary counseling and engaging in Ramadan fasting-tailored health and wellness improvement education, (4) maintaining a low to moderate level of regular physical activity can a have positive health outcomes, and (5) staying hydrated by consuming adequate fluid intake, especially water throughout the non-fasting intervals.

For future research, studies conducted on the health effects of fasting are recommended to focus exclusively on targeted variables such as culture differences, differences in fasting-specific dietary practices including food quality, effects of geographical regions and the length of the hours of daily fasting globally, effects of weather temperature variation on fasting, and the health effects of fasting on age and gender.

Author's contributions

The author read and approved the final manuscript.

\section{Funding}

No funding was received for conducting the present study or drafting its manuscript.

\section{Competing interests}

The author of the present study declares that there is no conflict of interest concerning the research design, data collection, manuscript drafting, publication, or application.

Received: 17 December 2019 Accepted: 27 April 2020

Published online: 11 May 2020

References

1. Rogers K. Fasting. Encyclopedia Britannica. https://www.britannica.com/ topic/fasting. (2016). Accessed 19 July 2019.

2. Grumett D, Muers R. Theology on the menu: asceticism, meat and Christian diet. 1st ed. Oxfordshire, UK: Routledge; 2010.

3. Shatenstein B, Ghadirian P. Influences on diet, health behaviors and their outcome in select ethnocultural and religious groups. Nutrition. 1998;14(2): 223-230. Available from: https://doi.org/10.1016/S0899-9007(97)00425-5.

4. CAl Editor. Fasting around the world. Cultural Awareness International. https://culturalawareness.com/fasting-around-the-world/. (2015). Accessed 22 July 2019.

5. Khazan O. The diet from God. The Atlantic. https://www.theatlantic.com/ health/archive/2013/11/the-diet-from-god/281816/. (2018). Accessed 5 June 2019.

6. Bloomer RJ, Kabir MM, Canale RE, Trepanowski JF, Marshall KE, Tyler M Farney TM, et al. Effect of a 21-day Daniel Fast on metabolic and cardiovascular disease risk factors in men and women. Lipids Health Dis. 2010;9: 94. Available from: https://doi.org/10.1186/1476-511X-9-94.

7. Esposito J. The Oxford history of Islam. Oxford, UK: Oxford University Press; 1999.

8. Foltz R. Religions of the Silk Road: premodern patterns of globalization. Basingstoke, UK: Palgrave Macmillan; 2010.

9. Lipka M, Hackett C. Why muslims are the world's fastest-growing religious group. Pew Research Center (n. page). http://www.pewresearch.org/facttank/2017/04/06/why-muslims-are-the-worlds-fastest-growing-religiousgroup/. (2017). Accessed 27 July 2019

10. Al-Sawy S, Al-Muslih A. Timeless fundamentals of Islam. Scotts Valley, California: CreateSpace Independent Publishing Platform; 2018.

11. Bernieh $\mathrm{BO}$, Mohamed $\mathrm{AO}$, Wafa $\mathrm{AM}$. Ramadan fasting and renal transplant recipients: clinical and biochemical effects. Saudi J Kidney Dis Transpl. 1994; 5:470-3.

12. Kadri N, Tilane A, El Batal M, Taltit Y, Tahiri SM, Moussaoui D. Irritability during the month of Ramadan. Psychosom Med. 2000;62:280-5.

13. Khaled BM, Belbraouet S. Effect of Ramadan fasting on anthropometric parameters and food consumption in 276 type 2 diabetic obese women. Int J Diabetes Dev Ctries. 2009;29(2):62-68. Available from: https://doi.org/10. 4103/0973-3930.53122 
14. Trepanowski JF, Bloomer RJ. The impact of religious fasting on human health Nutr J. 2010;9(1):57 Available from: https://doi.org/10.1186/1475-2891-9-57.

15. Aksungar FB, Eren A, Ure S, Teskin O, Ates G. Effects of intermittent fasting on serum lipid levels, coagulation status and plasma homocysteine levels. Ann Nutr Metab. 2005;49:77-82. Available from: https://doi.org/10.1159/ 000084739.

16. Hallak MH, Nomani MZ. Body weight loss and changes in blood lipid levels in normal men on hypocaloric diets during Ramadan fasting. Am J Clin Nutr. 1988;48:1197-210.

17. Fedail SS, Murphy D, Salih SY, Bolton CH, Harvey RF. Changes in certain blood constituents during Ramadan. Am J Clin Nutr. 1982;36:350-3.

18. Roky R, Chapotot F, Hakkou F, Benchekroun MT, Buguet A. Sleep during Ramadan intermittent fasting. J Sleep Res. 2001;10:319-27 Available from: https://doi.org/10.1046/j.1365-2869.2001.00269.x.

19. Bakhotmah BA. The puzzle of self-reported weight gain in a month of fasting (Ramadan) among a cohort of Saudi families in Jeddah, Western Saudi Arabia. Nutr J. 2011;10:84. Available from: https://doi.org/10.1186/ 1475-2891-10-84.

20. Ali Z, Abizari AR. Ramadan fasting alters food patterns, dietary diversity and body weight among Ghanaian adolescents. Nutr J. 2018;17(1):75. Available from: https://doi.org/10.1186/s12937-018-0386-2.

21. Ongsara S, Boonpol S, Prompalad N, Jeenduang N. The effect of Ramadan fasting on biochemical parameters in healthy Thai subjects. J Clin Diagn Res. 2017;11(9):BC14-BC18. Available from: https://doi.org/10.7860/JCDR/ 2017/27294.10634

22. Norouzy A, Salehi M, Philippou E, Arabi H, Shiva F, Mehrnoosh S, Mohajeri SM, et al. Effect of fasting in Ramadan on body composition and nutritional intake: a prospective study. J Hum Nutr Diet, 2013;26 Suppl 1:97-104. Available from: https://doi.org/10.1111/jhn.12042.

23. Ibrahim WH, Habib HM, Jarrar AH, Al Baz SA. Effect of Ramadan fasting on markers of oxidative stress and serum biochemical markers of cellular damage in healthy subjects. Ann Nutr Metab. 2008:53:175-181. Available from: https://doi.org/10.1159/000172979.

24. Taoudi BM, Roky R, Toufiq J, Benaji B, Hakkou F. Epidemiological study: chronotype and daytime sleepiness before and during Ramadan. Therapie. 1999:54(5):567-72.

25. Bahammam AS, Almushailhi K, Pandi-Perumal SR, Sharif MM. Intermittent fasting during Ramadan: does it affect sleep? J Sleep Res., 2014;23(1):35-43. Available from: https://doi.org/10.1111/jsr.12076.

26. Al-Hadramy MS, Zawawi TH, Abdelwahab SM. Altered cortisol levels in relation to Ramadan. Eur J Clin Nutr. 1988;42:359-62.

27. BaHammam A, Alrajeh M, Albabtain M, Bahammam S, Sharif M. Circadian pattern of sleep, energy expenditure, and body temperature of young healthy men during the intermittent fasting of Ramadan. Appetite. 2010; 54(20):426-9 Available from: https://doi.org/10.1016/j.appet.2010.01.011.

28. Brunner DP, Dijk DJ, Borbély AA. Repeated partial sleep deprivation progressively changes in EEG during sleep and wakefulness. Sleep, 1993; 16(2):100-113. Available from: https://doi.org/10.1093/sleep/16.2.100.

29. Iraki L, Bogdan A, Hakkou F, Amrani N, Abkari A, Touitou Y. Ramadan diet restrictions modify the circadian time structure in humans: a study on plasma gastrin, insulin, glucose, and calcium and on gastric pH. J Clin Endocrinol Metab, 1997;82(4):1261-1273. Available from: https://doi.org/10. 1210/jcem.82.4.3860

30. Shahid A, Shen J, Shapiro CM. Measurements of sleepiness and fatigue. J Psychosom Res., 2010;69(1):81-89. Available from: https://doi.org/10.1016/j. jpsychores.2010.04.001.

31. Shen J, Barbera J, Shapiro, CM. Distinguishing sleepiness and fatigue: focus on definition and measurement. Sleep Med Rev. 2006;10(1):63-76. Available from: https://doi.org/10.1016/j.smrv.2005.05.004.

32. Vanitallie TB. Stress: a risk factor for serious illness. Metabolism. 2002;51(6 Suppl 1):40-45. Available from: https://doi.org/10.1053/meta.2002.33191.

33. Roky R, Houti I, Moussamih S, Qotbi S, Aadil N. Physiological and chronobiological changes during Ramadan intermittent fasting. Ann Nutr Metab. 2004;48(4):296-303 Available from: https://doi.org/10.1159/ 000081076

34. Kalafat UM, Topacoglu H, Dikme O, Dikme O, Sadillioglu S, Erdede MO. Evaluation of the impact of the month of Ramadan on traffic accidents. Int J Med Sci Public Health. 2016; 5(35):543-546. Available from: https://doi.org/ 10.5455/ijmsph.2016.05112015173.

35. Khammash MR, Al-Shouha TF. Do road traffic accidents increase during the fasting month of Ramadan. Neurosciences (Riyadh). 2006;11(1):21-3.
36. Tolon $\mathrm{M}$, Chernoff, $\mathrm{H}$. The effect of fasting during Ramadan on traffic accidents in Turkey. CHANCE. 2013;20(2):10-18. Available from: https://doi. org/10.1080/09332480.2007.10722840.

37. Yıldırım-Yenier Z, Lajunen T, Özkan T. Driving in the fasting month of Ramadan: an observational study on speeding, horn honking, and using seat belts. Transportation Research Part F: Traffic Psychology and Behavior. 2016;42(3):562-8 Available from: https://doi.org/10.1016/j.trf.2015.05.001.

38. Hosseini SR, Hejazi K. The effects of Ramadan fasting and physical activity on blood hematological-biochemical parameters. Iran J Basic Med Sci. 2013; 16(7):845-9.

39. Patterson RE, Laughlin GA, LaCroix $A Z$, et al. Intermittent fasting and human metabolic Health. J Acad Nutr Diet. 2015;115(8):1203-1212. Available from: https://doi.org/10.1016/j.jand.2015.02.018.

40. Johnson JB, Summer W, Cutler RG, et al. Alternate day calorie restriction improves clinical findings and reduces markers of oxidative stress and inflammation in overweight adults with moderate asthma. Free Radic Biol Med. 2007:42:665-674. Available from: https://doi.org/10.1016/j. freeradbiomed.2006.12.005

41. Kul S, Savas E, Ozturk ZA, Karadag G. Does Ramadan fasting alter body weight and blood lipids and fasting blood glucose in a healthy population? A meta-analysis. J Relig Health. 2013;16:1217-1222. Available from: https:// doi.org/10.1007/s10943-013-9687-0.

42. Shehab A, Abdulle A, El Issa A, Al Suwaidi J, Nagelkerke N. Favorable changes in lipid profile: the effects of fasting after Ramadan. PLoS One. 2012;7(10):e47615.

43. Bouhlel E, Denguezli M, Zaouali M, Tabka Z, Shephard RJ. Ramadan fasting's effect on plasma leptin, adiponectin concentrations, and body composition in trained young men. Int J Sport Nutr Exer Metab. 2008; 18(6):617-27.

44. Ahmad S, Goel K, Maroof KA, Goel P, Arif M, Amir M, Abid M. Psychosocial behavior and health benefits of Islamic fasting during the month of Ramadan. J Community Medicine \& Health Education. 2012;2(9):21610711. Available from: https://doi.org/10.4172/2161-0711.1000178.

45. Lee JY, Wong CP, Tan CSS, et al. Type2 diabetes patient's perspective on Ramadan fasting: a qualitative study. BMJ Open Diabetes Res Care. 2017;5:e000365. Available from: https://doi.org/10.1136/bmjdrc-2016000365.

46. Toda M, Morimoto K, Nihon EZ. Effects of Ramadan fasting on the health of Muslims. J Nippon Eiseigaku Zasshi. 2000;54(4):592-596. Available from: https://doi.org/10.1265/jjh.54.592.

47. Pakkir MN., Jumale, A., Balasubramaniam, R. Adverse health effects associated with Islamic fasting: a literature review. Journal of Nutrition, Fasting, and Health. 2017; 5(3):113-118. Available from: doi: 10.22038/jfh. 2017.25419.1095.

48. NasrAllah MM, Osman NA. Fasting during the month of Ramadan among patients with chronic kidney disease: renal and cardiovascular outcomes. Clin Kidney J. 2014;7(4):348-353. Available from: https://doi.org/10.1093/ckj/ sfu046.

49. Alkandari JR, Maughan RJ, Roky R, Aziz AR, Karli U. The implications of Ramadan fasting for human health and well-being. J Sports Sci. 2012;30 Suppl 1:S9-19. Available from: doi: https://doi.org/10.1080/02640414.2012. 698298.

50. Hui E, Devendra D. Diabetes and fasting during Ramadan. Diabetes Metab Res Rev. 2010; (8):606-610. Available from: https://doi.org/10. 1002/dmrr.1137.

51. Topacoglu H, Karcioglu O, Yuruktumen A, Kiran S, Cimrin AH, Ozucelik DN, et al. Impact of Ramadan on demographics and frequencies of disease-related visits in the emergency department. Int J Clin Pract. 2005;59(8):900-905. Available from: https://doi.org/10.1111/j.1742-1241. 2005.00460.x.

52. Memari AH, Kordi R, Panahi N, Nikookar LR, Abdollahi M, Akbarnejad A. Effect of Ramadan fasting on body composition and physical performance in female athletes. Asian J Sports Med. 2011;2(3):161-166. Available from: https://doi.org/10.5812/asjsm.34754.

53. Tian HH, Aziz AR, Png W, Wahid MF, Yeo D, Constance Png AL. Effects of fasting during Ramadan month on cognitive function in Muslim athletes. Asian J Sports Med. 2011;2(3):145-153. Available from: https://doi.org/10. 5812/asjsm.34753.

54. Shephard RJ. The impact of Ramadan observance upon athletic performance. Nutrients. 2012;4(6):491-505. Available from: https://doi.org/10. 3390/nu4060491. 
55. Ennigrou S, Zenaidi M, Ben Slama F, Zouari B, Nacef T. Ramadan and customs of life: investigation with 84 adult residents in the district of Tunis. Tunis Med. 2001;79(10):508-14.

56. Shadman Z, Hedayati, M, Larijani, B, Akhoundan, M, Khoshniat, M.

Recommended guideline for designing and interpreting of Ramadan fasting studies in medical research. Journal of Nutrition, Fasting and Health, 2015; 3(4): 156-165. Available from: https://doi.org/10.22038/ffh.2015.6247.

57. Ismail S, Abdul Rahman H, Abidin EZ, et al. The effect of faith-based smoking cessation intervention during Ramadan among Malay smokers. Qatar Med J. 2017;2016(2):16. Available from: https://doi.org/10.5339/qmj. 2016.16

\section{Publisher's Note}

Springer Nature remains neutral with regard to jurisdictional claims in published maps and institutional affiliations.

Ready to submit your research? Choose BMC and benefit from:

- fast, convenient online submission

- thorough peer review by experienced researchers in your field

- rapid publication on acceptance

- support for research data, including large and complex data types

- gold Open Access which fosters wider collaboration and increased citations

- maximum visibility for your research: over $100 \mathrm{M}$ website views per year

At BMC, research is always in progress.

Learn more biomedcentral.com/submissions 